\title{
PROJETOS DE DESENVOLVIMENTO E TERRITÓRIOS TRADICIONAIS NO MARANHÃO, BRASIL: AMEAÇAS E PROCESSOS DE RESISTÊNCIAS
}

\section{DEVELOPMENT PROJECTS AND TRADITIONAL TERRITORIES IN MARANHÃO, BRAZIL: THREATS AND RESISTANCE PROCESSES}

\author{
Bartolomeu Rodrigues Mendonça* \\ Cíndia Brustolin"* \\ Elio De Jesus Pantoja Alves***
}

\section{Introdução}

0 avanço de grandes empreendimentos sobre o espaço rural maranhense tem provocado uma série de conflitos com povos e comunidades tradicionais. As mudanças registradas nos últimos cinquenta anos, alicerçadas na opção governamental por projetos desenvolvimentistas, pelo avanço das cercas e empreendimentos sobre espaços territoriais ocupados pelos grupos negros e indígenas, ou seja, pela expansão do capital nacional e internacional na região que envolve a Amazônia Legal, provocaram deslocamentos, perdas territoriais e assoreamento de rios e igarapés.

Em larga medida, territórios e comunidades tradicionais foram postos ao sacrifício em nome do desenvolvimento econômico promovido pelo Estado, em consórcio com empresas de grande poder de investimento e, em boa parte, com financiamentos vindos dos cofres públicos. Centenas de casos podem ser contabilizados no Maranhão,

\footnotetext{
* Professor da Universidade Federal do Maranhão - UFMA - (São Luís /MA/Brasil). Doutor em Ciências Sociais. E-mail: canapum@gmail.com.

** Professora da Universidade Federal do Maranhão - UFMA - (São Luís /MA/Brasil). Doutora em Sociologia. E-mail: cindiabrustolin@gmail.com

*** Professor da Universidade Federal do Maranhão - UFMA - (São Luís /MA/Brasil). Doutor em Ciências Humanas - Sociologia. E-mail: eliopantojalves@gmail.com
} 
como o caso de Piquiá de Baixo, em Açailândia/MA, que resiste à contaminação do complexo siderúrgico daquela cidade; o território étnico do povo negro de Alcântara/ MA e os deslocamentos relacionados à instalação da Base Aeroespacial de Alcântara, na década de 1980, e as novas investidas relacionadas a efetivação do funcionamento da base; os territórios das comunidades Pode Ser e Salva Terra I e II, no município de Bacabeira/MA, apagados pelo projeto de instalação da Refınaria Premium da Petrobrás, obra que sequer foi efetivada; as terras dos povoados de trabalhadores rurais de Imperatriz e Balsas, expulsas ou arrasadas pelo veneno do agronegócio; os quilombolas e indígenas atravessados pelo Corredor Carajás, com espaços de roças suprimidos, igarapés entupidos, pessoas atropeladas; as comunidades rurais de São Luís, que resistiram à instalação de um polo siderúrgico, se organizam contra a instalação de um novo porto privado na região, e ainda lutam pela criação de uma RESEX (Reserva Extrativista) e contra a alteração do Plano Diretor da cidade, que prevê suprimir 40\% (quarenta por cento) da Zona Rural do Município.

Argumentamos que os legados da experiência colonial, da escravidão e as discussões sobre a colonialidade do poder são centrais para entendermos o avanço de empreendimentos capitalistas sobre o campo maranhense e as resistências e lutas de camponeses submetidos a essas lógicas expropriadoras (MENDONÇA, 2017; SBRANA, 2015; JESUS, 2014). Nesse sentido, Mendonça (2017) sugere que é preciso trazer ao tempo presente as lutas, os gritos, as conquistas que emolduram as formas de continuar a existir de povos e comunidades que foram, há muito, sentenciadas à extinção pelos grupos hegemônicos desde a empresa colonial, passando pela monopolista, até a fase do capital financeiro e rentista. Assim, podemos compreender que "o limite entre o atual e o inatual está longe de se ajustar necessariamente pela média matemática de um intervalo de tempo", segundo Mendonça (2017), a partir de Marc Bloch (2001, p. 61).

Neste artigo, exploramos dimensões da colonialidade de poder expressas nos processos de dominação engendrados na instalação de empreendimentos e processos de resistência de povos e comunidades tradicionais a partir de pesquisas realizadas na área rural de São Luís, com comunidades tradicionais de pescadores e agricultores, e em Itapecuru Mirim, com as lutas quilombolas, especificando um território. A noção de repertórios de ação auxiliará a sistematização e a análise dos processos de resistência em jogo.

Os trabalhos de pesquisa foram executados por pesquisadores ligados ao GEDMMA (Grupo de Estudos: Desenvolvimento, Modernidade e Meio Ambiente) durante os últimos quatro anos, e consistiram em entrevistas semiestruturadas, análise documental e na participação em reuniões e audiências envolvendo comunidades da Zona Rural de São Luís e quilombolas de territórios negros de Itapecuru Mirim.

Organizamos o artigo em dois eixos: notas sobre a colonialidade/modernidade no Maranhão e as formas de expressão da colonialidade e os processos de resistência em duas situações: dimensões da peleja das comunidades do Sudoeste de São Luís/MA pela efetivação da Resex Tauá-Mirim e da luta pela garantia do território quilombola de Santa Rosa dos Pretos, em Itapecuru Mirim. 


\section{A colonialidade e a expansão capitalista}

Nos processos de expropriação territorial de grupos e povos tradicionais no Maranhão, relacionados à expansão do capital nacional e internacional, são acionadas estruturas coloniais que permitem o gerenciamento dos espaços territoriais necessários à instalação de empreendimentos e de estruturas logísticas (rodovias, estradas de ferro, portos) para o escoamento de mercadorias para o exterior, em detrimento de outras formas de reprodução social e cultural nas localidades. A colonialidade se expressa de distintas formas, como na relativização constante de dispositivos legais, ou mesmo na produção de sua interpretação; em negociações assimétricas, como a imposição de uma venda desvantajosa de terras; nas promessas de emprego, de progresso e desenvolvimento para todos, a partir do sacrifício de alguns; na ação violenta de derrubada de casas e entupimento de igarapés.

As políticas desenvolvimentistas constituem-se em estratégias importantes na imposição das lógicas expansionistas, sustentando a necessidade da destinação de espaços territoriais para a instalação de infraestruturas logísticas ligadas principalmente à mineração e ao agronegócio no estado. As obras são projetadas sobre territórios de grupos negros, indígenas, pescadores tradicionais reivindicados para delimitação, titulação, criação de reservas extrativistas. Na construção da possibilidade de dispor de terras ocupadas ou reivindicadas para demarcação, para a instalação de empreendimentos, são aprimoradas téc- nicas de dominação que acionam estruturas raciais presentes em processos coloniais e as trazem como componentes fundamentais da reprodução do sistema capitalista.

Pensemos, então, a gestão dos grupos e dos povos tradicionais, que podem ser operadas a partir de legislações, reuniões, deslocamentos, da inviabilização da vida no local por meio do entupimento de igarapés e da eliminação de espaços de roças, pela destruição de casas, relacionada ao exercício do poder soberano a partir de instituições que operam em nome do desenvolvimento; por meio do estado, de empresas privadas, de fazendeiros e políticos locais. As posturas críticas ao desenvolvimento ${ }^{1}$ têm discutido a relação entre programas e políticas de cunho desenvolvimentista com estratégias de dominação que se ancoram na colonialidade e nos dispositivos raciais. Nesse sentido, Mignolo (2008, p. 293) propõe relações entre desenvolvimento e a lógica da colonialidade.

"Desenvolvimento" foi - como sabemos na América do Sul e no Caribe, a palavrachave da terceira onda dos planos globais do após $2^{\circ}$ Guerra Mundial, quando os EUA tomaram a liderança que era da Inglaterra e da França, e substituíram a missão de civilização dessas pela sua própria versão de modernização e desenvolvimento. Ficou aparente, lá pelo fim dos anos sessenta e início dos setenta - com a crise do Estado do Bem-estar (Welfare State) -, que "desenvolvimento" era um outro termo na retórica da modernidade para esconder a reorganização da lógica da colonialidade: as novas formas

1. Como Escobar (2007), entre outros. 
de controle e exploração do setor do mundo rotulado como Terceiro Mundo e países subdesenvolvidos. A matriz racial de poder é um mecanismo pelo qual não somente as pessoas, mas as línguas e as religiões, conhecimentos e regiões do planeta são racializados. Ser subdesenvolvido não é como ser um indígena das Américas, Austrália e Nova Zelândia? Ou um negro da África? Ou muçulmanos do mundo árabe? Ser das colônias do Segundo Mundo (ex., Ásia Central e Cáucaso) não era, de uma certa forma, ser tão invisível como as colônias do império de segunda classe, uma racialização escondida sob a expressão "Segundo Mundo”?

Na tentativa de trazer dimensões da colonialidade e dispositivos intrínsecos ao "gerenciamento das populações" no Maranhão, exploramos também as possibilidades analíticas da noção de biopolítica proposta em Foucault (1999, p. 307), que considera as relações entre o racismo e a função assassina do Estado:

A raça, o racismo, é a condição de aceitabilidade de tirar a vida numa sociedade de normalização. [...] A função assassina do Estado só pode ser assegurada, desde que o Estado funcione no modo do biopoder, pelo racismo. [...] a importância vital - do racismo no exercício de um poder assim: é a condição para que se possa exercer o direito de matar. [...] É claro, por tirar a vida não entendo simplesmente o assassínio direto, mas também tudo o que pode ser assassínio indireto: o fato de expor à morte, de multiplicar para alguns o risco de morte ou, pura e simplesmente, a morte política, a expulsão, a rejeição, etc.

Portanto, buscamos discutir estratégias de poder relacionadas à classificação dos espaços territoriais, à hierarquização de indivíduos, grupos e comunidades para fins de exploração, expropriação e deslocamentos forçados, e mostrar suas relações com dimensões da colonialidade.

Será acionada, para discutir processos de resistência ao avanço de empreendimentos sobre os territórios tradicionais, a noção de repertórios de ação. Inspiramo-nos nos escritos de Charles Tilly, a partir da obra From mobilization to revolution, de 1978, e de seus intérpretes. Repertório remete ao conjunto de formas de ação coletiva, ou seja, ações compartilhadas e dotadas de sentido pelos sujeitos em suas agências nos diferentes contextos históricos, considerando também a dimensão cultural das coletividades e de seus interesses. Alonso (2012) propõe três passos sobre o uso desse conceito por Tilly. 0 primeiro, cujo termo aparece como repertórios de ações coletivas, remonta aos escritos de 1970; o segundo, repertório do confronto, nos anos de 1990 e, por último, repertório e performance, nos anos 2000. Ao longo desse período, o termo Repertório foi sendo atualizado, uma vez que as ações coletivas refletem a dinâmica das mobilizações e lutas políticas de cada época, bem como a incorporação das críticas pelo autor às suas teorias. Alonso (2012) nota também maior adesão da teoria à capacidade de ação dos sujeitos e menos influência ou determinações da estrutura sobre as ações coletivas.

0 uso da noção de repertórios neste artigo serve de base para descrever e discutir algumas formas de resistências e de enfrentamentos a partir de estudos dos autores e colaboradores no âmbito do Grupo de Estudos: Desenvolvimento, Modernidade e Meio Ambiente (GEDMMA/UFMA). São pesquisas que apontam a inserção destas ações no campo de conflitos que se esten- 
dem no tempo, como mostra Jesus (2014), ao estudar os processos de resistências na área rural de São Luís, a exemplo da vivência dos moradores da comunidade de Rio dos Cachorros, tendo como pressuposto que esta vivência se constrói no enfrentamento "ao aborto de suas existências, algo imposto historicamente pelos diversos grupos dominantes, pelas variadas políticas de apagamento, pelas inúmeras escritas da história que conscientemente esquecem desses sujeitos".

\section{A autonomia da resistência no território da Resex de Tauá-Mirim - São Luís/MA}

Desde os anos de 1980, as comunidades rurais localizadas na porção sudoeste do município de São Luís - MA sofrem ameaças de deslocamentos compulsórios ${ }^{2}$ para instalação de empreendimentos industriais e portuários atraídos pela estrutura do Complexo Portuário de São Luís ${ }^{3}$. 0 Complexo Portuário é, por sua vez, integrado à logística mina-ferrovia-porto da antiga Companhia Vale ${ }^{4}$, hoje Vale S.A., que o interliga à mina de ferro de Carajás no sudeste do Estado do Pará.

Conforme Sant'Ana Júnior e Alves (2018), a Amazônia Oriental ${ }^{5}$ brasileira, desde a década de 1970, vem sendo marcada por profundas transformações que têm como um dos principais indutores o Programa Grande Carajás (PCG), instalado no período da ditadura civil/militar, iniciada em 1964, partindo de impulsos iniciais do Governo Federal brasileiro e iniciativas da Companhia Vale do Rio Doce (CRVD), "com vistas à extração, transporte e exportação do minério de ferro de altíssima qualidade

2. Ilha do Maranhão é o nome oficial da ilha onde se situa o município de São Luís. É também chamada de Upaon-Açú (Ilha Grande), nome que foi designado pelos povos indígenas antes do período colonial. A Ilha do Maranhão é constituída por um arquipélago com mais de cinquenta ilhas com variadas origens e dimensões. A maior delas é a Ilha de São Luís, onde se localiza a capital do Maranhão. Na Ilha do Maranhão, estão localizados os municípios de São Luís, Raposa, Paço do Lumiar e São José de Ribamar (MARANHÃO, 2004). 3. 0 Complexo Portuário de São Luís é formado por três portos: Porto do Itaqui (administrado pela estatal estadual Empresa Maranhense de Administração Portuária - EMAP), Ponta da Madeira (pertencente à Cia. Vale) e Porto da Alumar (pertencente ao Consórcio de Alumínio do Maranhão, formado pelas empresas Alcoa, BHP Billiton e Rio Tinto Alcan). Está localizado na baía de São Marcos, a $11 \mathrm{~km}$ do centro de São Luís, capital do Maranhão.

4. A Vale é uma empresa brasileira privada de capital aberto desde 1997, quando foi privatizada. É a maior produtora de minério de ferro do mundo e a segunda maior de níquel, produzindo também cobre, carvão, manganês, ferro-liga, fertilizantes, cobalto e metais do grupo da platina. Atua também no setor de Logística, Siderurgia, Energia e Fertilizantes. Está presente em 37 países, possui acionistas distribuídos em todos os continentes e tem ações nas bolsas de São Paulo, Nova York, Hong Kong, Paris e Madrid. Até 2008 era denominada Companhia Vale do Rio Doce quando passou a usar o nome Vale; é a maior empresa do Brasil em volume de exportações. Foi criada em 1942, no governo Getúlio Vargas (http://www.vale.com/brasil/PT/business/Paginas/default.aspx. Acesso em 30.04.2018.).

5. A Amazônia Oriental é composta pelos Estados do Pará, Amapá, Tocantins e parte do Estado de Mato Grosso e parte do Estado do Maranhão. 
e outros minérios das gigantescas minas localizadas no sudeste do estado do Pará [...]” (SANT ANA JÚNIOR; ALVES, 2018, p. 260).

A produção mineral tem sido, portanto, um grande vetor de transformações, delineando, em grande medida, as políticas de desenvolvimento no estado. E ainda que no processo de redemocratização dos países latino-americanos, e especialmente no Brasil, as conquistas obtidas por pressões de movimentos sociais tenham levado à criação de canais de participação política, após a Constituição de 1988, a agenda dos governos locais permanece sob a influência dos agentes econômicos que dão a tônica aos processos de decisão. No caso da Amazônia Oriental, isto pode ser evidenciado na submissão/conivência dos governos locais aos interesses econômicos (articulação entre elites governistas e empresas) que atuam em diferentes escalas, regional, nacional e internacional, submetendo as normativas e os interesses coletivos aos interesses privados, cuja condição é fundamental para a expansão do capitalismo mundial que $\mathrm{W}$. Robinson (2013, p. 31) denomina de "capital transnacional”, que opera por meio de circuitos globais de acumulação.

Setores dos governos estadual e municipal, articulados aos grupos empresariais locais e nacionais, atuam conforme e integradamente aos interesses de grupos inseridos nos circuitos e mercados globais. Neste caso, agentes econômicos ligados ao mercado de commodities minerais e de outros bens interferem nas políticas urbanas recorrentemente, pressionando a gestão municipal e os respectivos espaços públicos deliberativos (Conselho da Cidade, audiências públicas, revisão do Plano Diretor e alterações na Lei Municipal de Zoneamento, Parcelamento, Uso e Ocupação do Solo Urbano e nas políticas urbanas da cidade etc.), no sentido de esvaziar a participação popular nos processos decisórios. Nesta situação, é válido notar as características desse processo de submissão do interesse público local aos interesses do capital através do que E. Gudynas (2015; p. 15) denomina de efeitos derrame:

Los "efectos derrame" de los extractivismos se despliegan mucho más allá de la localización espacial de cada emprendimiento, no aluden a los impactos locales en un sitio, sino a afectaciones que se pueden repetir en muchas otras zonas del país. A su vez, también se "derraman" más allá de las medidas específicas propias de cada emprendimiento, afectando los entendimientos y sentidos de diversas políticas públicas, como las ambientales, sociales o económicas, así como a los sentidos por los cuales se entiende el desarrollo, la política, la justicia, la democracia y la Naturaleza.

Os efeitos não se limitam à dimensão da gestão dos recursos naturais, estão relacionados às dimensões político-administrativa dos poderes instituídos localmente. Como observou Zhouri (2018, p. 18), os grandes projetos envolvendo a megamineração se constituem numa "arena de conflitos envolvendo grupos locais, setores do Estado, corporações, instituições, movimentos sociais, pesquisadores de diferentes formações em várias posições e escalas”.

Na cidade de São Luís, podemos dizer que a intervenção do grande capital nas políticas de desenvolvimento está diretamente relacionada com a instalação da fábrica de alumínio da Alcoa (Companhia Americana de Aluminio, atualmente ALUMAR, Companhia de Alumínio do Maranhão), que expropriou/ocupou $12 \%$ do território da Ilha do Maranhão, correspondente a 50\% 
do Distrito Industrial de São Luís (CÁRITAS BRASILEIRA, 1983) e com a construção da Estrada de Ferro Carajás, com 892 km de extensão, ligando a Serra dos Carajás, no município de Paraopebas, no sudoeste do Pará, ao Complexo Portuário de São Luís e implicou no deslocamento de pelo menos 14 comunidades rurais, aproximadamente 20.000 pessoas (ADRIANCE, 1996).

Tratam-se de projetos viabilizados aos moldes coloniais, a partir da tomada dos territórios e dos recursos das comunidades tradicionais. Ambos projetos foram originalmente concebidos entre as décadas de 1960 a 1980 e implementados na esteira das políticas de desenvolvimento do Governo Federal para a Amazônia Oriental, sob a justificativa da "integração" da região à econômica nacional. Entretanto, factualmente, objetivou-se atrelar de forma sistêmica a exploração dos recursos naturais da região, localizados em territórios de comunidades e de povos tradicionais da Amazônia Oriental, à exportação e ao controle das multinacionais, com apoio do estado brasileiro, através de incentivos fiscais e estruturas logísticas de escoamento da produção (FIORELO, 2006).

No entanto, consideramos também como efeito derrame os processos contra-hegemônicos que se constroem contra essa expansão de empreendimentos sobre os territórios tradicionais, na medida em que trazem à tona as ações reativas dos grupos sociais atingidos que exigem direitos por meio de diferentes formatos de ações coletivas. Ora dialogam com as institucionalidades (exemplo das audiências públicas, negociações e reivindicações junto aos órgãos púbicos), ora operam pela via da autonomia política (ocupações de órgãos públicos, bloqueios de estradas e avenidas, passeatas e protestos). Em São Luís, nesse mesmo contexto, se revela a outra face do desenvolvimento que, por um lado, produziu conflitos fundiários, destruição ambiental, desmantelamento das comunidades rurais e de pescadores e o surgimento de favelas e, por outro, gerou processos de resistência, que produziram importantes repertórios de ações coletivas (ALVES, 2014).

Nos anos de 1980, foi criado o Comitê de Defesa da Ilha que, atuando junto às organizações comunitárias e com as Comunidades Eclesiais de Base (CEBs), realizaram trabalho de educação popular, denunciando a destruição ambiental e o deslocamento de comunidades rurais, a exemplo, da comunidade de Igaraú, que teve seu território diretamente atingido pela fábrica de alumínio da ALCOA e se tornou símbolo de resistência popular (EGLISH, 1984), fonte de inspiração para as contínuas lutas das comunidades contra empreendimentos industriais ao longo dos anos de 1990, com a expansão de empreendimentos industriais e portuários na zona rural.

Entre os anos de 1990 e 2000, ocorreu um novo avanço das atividades industriais e portuárias: inúmeras empresas ligadas principalmente ao setor minero-metalúrgico, industrial e empresas de operações de logísticas foram atraídas para a área onde se situa o Complexo Portuário, justamente, na porção sudoeste da grande ilha. Observamos que em momentos de discussões públicas em espaços deliberativos e/ou consultivos, tais como audiências públicas e reuniões do Conselho da Cidade de São Luís (CONCID), pautando o planejamento urbano da cidade e a revisão do Plano Diretor, a expansão capitalista tem sido justificada a partir da promessa de desenvolvimento econômico local e da classificação dos espaços territoriais das comunidades tradicionais como espaços com "vocação 
portuária" e/ou "vocação metalúrgica". Tais posturas têm sido questionadas pelos movimentos sociais e por moradores e lideranças das comunidades rurais diretamente afetadas (ALVES, 2016; SANT"ANA JÚNIOR, 2018).

\subsection{0 processo de autonomização político territorial - o Conselho Gestor da Reserva Extrativista Tauá-Mirim em São Luís-MA}

Conforme relatos de lideranças de comunidades da zona rural de São Luís, por volta dos anos de 1990, as comunidades passaram a problematizar a escassez dos recursos naturais e as atividades produtivas: a pesca e o extrativismo marinho, o extrativismo mineral (pedra, areia, barro) e vegetal e, sobretudo, a redução das áreas de manguezal. Algumas famílias que trabalhavam com extração mineral e extração de madeiras do mangue tiveram de suspender estas atividades em função dos prejuízos ao ambiente, além do prejuízo que já sofriam pelo impacto das grandes indústrias. Esta "percepção" levou a um processo de mobilização política através das lideranças locais, entre estas, àquelas já engajadas em movimentos de pescadores, em torno de um projeto político unificado de criação de uma Unidade de Conservação na modalidade Reserva Extrativista ${ }^{6}$ em função das especificidades dos ecossistemas e dos grupos sociais que vivem na região.

Denominada inicialmente de Reser- va Extrativista do Taim, e posteriormente renomeada para Tauá-Mirim (RESEX de Tauá-Mirim), em 2003, os moradores dos povoados do Taim, de Cajueiro, de Rio dos Cachorros, do Limoeiro e de Porto Grande, por meio de um abaixo-assinado, solicitaram ao IBAMA a criação da RESEX, na Zona Rural II de São Luís. O IBAMA instaurou o processo de constituição da RESEX ${ }^{7}$ em 2003, e três anos depois realizou a audiência pública para consultar a população acerca do pedido de inclusão dos povoados na reserva (MIRANDA, 2009). Após uma série de reuniões mobilizadas por lideranças comunitárias, bem como no processo de negociação com o IBAMA, foi definido que a área da RESEX é de 16.663,55 hectares, com perímetro aproximadamente de 71,21 $\mathrm{km}$, na porção sudoeste da Ilha do Maranhão, situada na área antes reivindicada para instalação do polo siderúrgico (IBAMA, 2007).

Na contraposição do discurso da "vocação portuária" e da "vocação siderúrgica" da localidade, em 2002, a reivindicação da Reserva Extrativista de Tauá-Mirim foi retomada com a iminência de instalação do polo siderúrgico na zona rural de São Luís. Entretanto, o polo siderúrgico foi inviabilizado em grande medida pela pressão realizada pelos movimentos de reação à instalação, protagonizados pelas lideranças comunitárias, que, se aliando às outras redes de movimentos sociais e setores da sociedade civil de São Luís, criaram, a par-

6. Reserva Extrativista é uma modalidade de unidade de conservação ambiental prevista no Sistema Nacional de Unidade de Unidade de Conservação (SNUC), conforme está instituído pela Lei nº 9.985 , de 18 de julho de 2000.

7. Processo no 02012.001265/2003-73, de 22 de agosto de 2003. 
tir de 2004, um importante movimento de resistência mais amplo, denominado Movimento Reage São Luís (ALVES, 2014).

0 empreendimento siderúrgico, alvo principal deste movimento, foi objeto de intensos debates entre 2004 e 2006, pois seria composto de três usinas siderúrgicas a serem instaladas em uma área de 2.471,71 ha, o que implicaria no deslocamento de vários povoados ameaçados pela instalação das plantas das siderúrgicas (Cajueiro, Parnauaçú, Andirobal, Taim, Rio dos Cachorros, Porto Grande, Vila Maranhão, Ananandiba, Colier, São Benedito, Vila Madureira e Camboa dos Frades), afetando cerca de 14.380 pessoas, conforme um levantamento realizado pela Associação de Moradores do Taim, em 2004.

Como desdobramento do processo de mobilização contra a instalação do polo siderúrgico e sua inviabilização, a luta pela RESEX ganhou força com a adesão de vários movimentos sociais em sua defesa, obtendo também mais visibilidade política na agenda local. Entretanto, é importante destacar que, mesmo com a inviabilização de um grande polo siderúrgico, a área tornou-se objeto de intensa especulação imobiliária, gerando conflitos no interior das comunidades e, ao mesmo tempo, abrindo portas para instalação de empreendimentos menores, como é o caso das mineradoras que exploram pedra e areia, com impactos socioambientais relevantes na medida em que ocorre a supressão de áreas de manguezais e a destruição de igarapés e de áreas de recarga de aquíferos, fundamentais aos modos de vida locais.

Já no final de 2014, um novo empreendimento começou a ser instalado na localidade. A comunidade do Cajueiro passou a sofrer ameaças de deslocamento de seu território para a construção de um Terminal de Uso Privado (TUP) da empresa WPR - São Luís Gestão de Portos e Terminais Ltda, que foi anunciado e autorizado oficialmente pelo Ministério dos Transportes, posteriormente, em janeiro de 2016, com apoio do Governo do Maranhão e da Prefeitura de São Luís, com previsão de investimentos governamentais de $\mathrm{R} \$ 1,782$ bilhão ${ }^{8}$. Desde 2014, os moradores da comunidade do Cajueiro passaram a sofrer intimidações por parte de seguranças armados de uma empresa de segurança, conhecida como Leões Dourados, que estava a serviço da WPR, principalmente, na área da praia de Parnauaçú, pleiteada para construção do porto.

Em outubro de 2014, os moradores do Cajueiro, através de União de Moradores Proteção do Bom Jesus do Cajueiro, uniram-se às lideranças de comunidades vizinhas, realizando reuniões referentes à situação, quando tiveram apoio de pesquisadores do Grupo de Estudos: Desenvolvimento, Modernidade e Meio Ambiente (GEDMMA/ UFMA), que realizavam pesquisa de campo naquele momento na comunidade, e da Comissão Pastoral da Terra (CPT).

8. http://www.brasil.gov.br/infraestrutura/2016/01/governo-autoriza-novo-terminal-de-uso-privado-no-maranhao. Acesso em 12.01.2016. 
Entre junho e outubro de 2014, foram realizadas dez reuniões pelos moradores e lideranças do Cajueiro sobre as ameaças, seguidas de ações como o bloqueio da BR -135, com a presença da Polícia Militar e da imprensa, gerando visibilidade da situação. Em 16 de outubro, os moradores do Cajueiro e de comunidades vizinhas impediram a realização de uma audiência pública promovida pela WPR - São Luís Gestão de Portos e Terminais Ltda., na Escola Gomes de Sousa, na Vila Maranhão, que pretendia viabilizar o licenciamento do porto. Os moradores questionaram o descumprimento de prazos legais para convocação pelo governo do estado, da audiência pública, e à indisponibilidade do EIA-RIMA (Estudo e Relatório de Impactos Ambientais) elaborados pela empresa para consulta pública.

Em contraposição, a Secretaria Estadual de Meio Ambiente convocou, para o dia 29 de outubro/2014, uma nova audiência pública, no Comando Geral da Polícia Militar. Desobedecendo a orientação oficial, a União de Moradores do Cajueiro convocou, na mesma data e horário (29.10.2014), uma audiência popular na sede da União dos Moradores do Cajueiro. Pelo menos duzentas pessoas estiveram presentes, dentre estas, representantes de diferentes setores, entidades e instituições, tais como a Comissão Pastoral da Terra (CPT), a Irmãs de Notre Dame, professores, pesquisadores e estudantes universitários, a Defensoria Pública do Estado (DPE), o Ministério Público Estadual (MPE), a Delegacia de Conflitos Agrários, o deputado estadual Bira do Pindaré (PBS), o representante da vereadora Rose Sales (PCdoB) e a Central Popular e Sindical (CSP-Conlutas). Nesta Audiência Popular, foi pautado o descumprimento de prazos legais para convocação de audiências públicas e a indisponibilidade do EIA-RIMA
(Estudo e Relatório de Impactos Ambientais) e, também, as violações aos direitos dos moradores. Em trecho de uma entrevista realizada durante esta Audiência Popular no Cajueiro, um morador narra a situação vivenciada naquele contexto de ameaças:

[...] se você quer construir na sua área, eles não querem deixar entrar material. Eu acho isso errado porque se você não vendeu a sua área você tem direito de trabalhar na sua área e eles não querem deixar você trabalhar, fazer sua casa e tal. Isso eu acho errado, né? Porque se você já vendeu sua área, eles têm direito de chegar e mandar, né? Mas como eles ainda não indenizaram, não me indenizaram, eles têm de direito de chegar e mandar, pedir, mas e aí? (SANT'ANA JÚNIOR e ALVES, 2018, p. 284)

Em 18 de dezembro de 2014, vinte e uma casas foram demolidas na área do Parnauaçú; tal ação foi questionada judicialmente por advogados da Comissão Pastoral da Terra (CPT), pois não havia documento de decisão judicial ou intimação legítimo. Ademais, o juiz que havia expedido estava afastado da Vara, sendo que esta ação, conforme relatos de moradores, foi acompanhada pela Polícia Militar. Posteriormente, entre 8 e 23 de dezembro de 2014, após uma série de reuniões, os moradores do Cajueiro e apoiadores acionaram a Secretaria de Segurança Pública do Estado, denunciando a situação e exigindo investigação e punição dos responsáveis pela ação. Um novo bloqueio da BR-135 também foi realizado em 23 de dezembro de 2014. Houve a presença da imprensa e da Polícia Federal, que retirou os seguranças armados da empresa Leões Dourados, naquele contexto, já considerados como "milicianos" pelos moradores, pois a empresa não tinha registro e nem permissão para exercer a função de empresa de segurança. 
Mesmo com o conflito instalado, em 26 de dezembro de 2014, a Secretaria de Estado e do Meio Ambiente e Recursos Naturais - SEMA, concedeu Licença Prévia (LP) à WPR Gestão de Portos e Terminais, LTDA. para instalação do terminal portuário privado, atestando a viabilidade locacional do projeto (Processo 108.205/2014), e no dia 30 de dezembro de 2014, o governador interino do Maranhão, Arnaldo Melo, assinou um decreto de desapropriação de uma área de $322.977,60 \mathrm{~m}^{2}$ no Parnauaçú, em favor da WPR Gestão de Portos e Terminais, LTDA, determinando "o caráter de urgência para fins de imissão provisória dos bens" (DECRETO no 30.610, de 30.12. 2014).

Com a posse do então eleito governador do estado, Flávio Dino (PC do B), no início de 2015, ocorreram várias reuniões, sendo que uma destas reuniões para retomada de negociações com o novo governo contou com a presença do Secretário de Estado e Segurança Pública do Maranhão, do Secretário de Estado e Igualdade Racial (SEIR), de representantes da Secretaria de Direitos Humanos e Participação Popular (SEDIHPOP) do novo governo, além de parlamentares. A pressão resultou na suspensão do decreto de liberação da obra pelo novo governador.

A obra, entretanto, até o presente, avança sobre os terrenos dos moradores com supressão de áreas de mangues, brejos e de babaçuais, acirrando ainda mais um conflito que se arrasta desde 2014. Vazzi (2017, p. 168), que analisou o processo de "judicialização no confronto" no caso do
Cajueiro, observa:

A empresa busca crescentemente agregar mais agentes a sua engrenagem de necropolítica, distribui essa "soberania de morte" em uma estrutura de capilaridade por uma tecnologia de exercício de micropoderes que ajuda a constituir o Cajueiro como colônia para seus interesses de espoliação. Enquanto isso e, por sua vez, o "Estado em ação" anuncia - oficialmente ou não - que o Cajueiro, está marcado como zona de atendimento a uma ordem global, usando dispositivos de segurança para a proteção de um sistema internacional de divisão do trabalho e de globalização e interesses mundiais de mercado. Com isso, a criação do terror e os decretos de sacrifício passam a ser práticas naturalizadas.

Agentes do Estado, atrelados jurídico e institucionalmente aos interesses privados, agem no sentido viabilizar a qualquer custo as obras. Na conformação do confronto, a disputa exige o acionamento de diversos campos e repertórios de ação política (VAZZI, 2017; ALVES; MARTINS, 2016).

No Cajueiro, a relação entre o caráter sagrado e a categoria "tradicional" configura novas articulações e repertórios acionados concomitantemente. A reivindicação do Terreiro do Egito, como território sagrado, e sua relação com o reconhecimento do patrimônio material e imaterial compõem um importante repertório de ação com vistas a assegurar direitos territoriais ${ }^{9}$.

9. Ver: Relatório Socioantropológico. RESEX de Tauá-Mirim: Cajueiro e outras comunidades tradicionais na luta por justiça e direitos territoriais, Zona Rural II, São Luís/MA - Brasil, GEDMMA-UFMA, 2014); Mundicarmo Ferretti (2015) e Alves e Martins (2016). 
No desdobramento das discussões sobre a questão da garantia territorial, o Morro do Egito foi se constituindo como uma pauta relevante, considerando a dimensão sagrada dessa área pela existência do Terreiro do Egito. 0 Morro do Egito é uma elevação de terra às margens da baía de São Marcos, onde está localizado o espaço do antigo Terreiro do Egito, considerado um lugar sagrado pelos praticantes do Tambor de Mina, religião de matriz africana muito marcante no Maranhão. Os relatos orais de pais e de mães de santo que ali iniciaram suas atividades religiosas indicam que aquela área fora ocupada, no século XIX, por negros quilombolas, que também realizavam seus cultos ${ }^{10}$ (ALVES; MARTINS, 2016).

Entre julho e agosto de 2015, as lideranças do Cajueiro solicitaram apoio do GEDMMA e do GPMINA para uma pesquisa da genealogia dos filhos, pais e mães de santo herdeiros do Terreiro do Egito. Após o levantamento documental, os descendentes foram contatados e convidados para participação de um ato simbólico ocorrido na manhã de 22 de novembro de 2015, com a leitura de uma Carta Aberta, "exigindo a preservação do Terreiro do Egito enquanto território sagrado e do Cajueiro como comunidade tradicional e uma caminhada com a presença de moradores da área, pais, mães e filhos de santo, pesquisadores e membros de movimentos sociais". Após a leitura da Carta e pronunciamentos das lideranças locais, de pesquisadores e dos membros de terreiros de mina, foi realizada a caminhada da União de Moradores ao terreiro do Egito, onde foi levantado o mastro com uma bandeira branca, o que significou a retomada e a demarcação do território sagrado (ALVES; MARTINS, 2016). E ainda, segundo a análise de Vazzi:

Nesse processo de resistência e em seus repertórios de luta, não é por acaso, também, que os múltiplos significados históricos, figuras complexas de diferença e identidade, inclusão e exclusão e simbologias culturais do Terreiro do Egito são retomadas, em lembrança das lutas ancestrais contra a escravidão e pela liberdade, contra as discriminações de crenças, exercício religioso. Esse processo fortalece a luta contra o porto, classificada por moradores como uma batalha de "Davi contra Golias", num exercício de espiritualidade mesclado à resistência contemporânea, com a retomada e proteção do território sagrado, a convocação das forças da natureza e da ancestralidade, da herança de saberes, cosmogonias e culturas, para expressões de uma crítica colonial (VAZZI, 2017, p. 258).

Posteriormente, com a intensificação das mobilizações em defesa do Cajueiro, e a unificação das lideranças comunitárias, foi formado um coletivo mais amplo com participação de diversos movimentos e entidades que procuraram a Defensoria Pública do Estado do Maranhão, e obtiveram, também, orientação e assessoria jurídica da 
CPT e apoio de pesquisadores, passando a pressionar o governo estadual, o que resultou no envio provisório de viaturas da Polícia Militar, através da Secretaria Estadual de Segurança Pública, em princípio para garantir a segurança dos moradores e o direito de ir e vir, uma vez que estavam sendo ameaçados pelos seguranças da empresa. Entretanto, esta ação policial não teve continuidade e a empresa continuou ameaçando os moradores e avançando nos desmatamentos, ao mesmo tempo, impedindo o trânsito livre dos moradores, sob a alegação de que os terrenos haviam sido comprados pela empresa.

Mais uma assembleia popular foi realizada em maio de 2015, desta vez na Casa das Águas, na comunidade do Taim, em grande medida impulsionada pela repercussão e iminente ameaça ao Cajueiro, contando com a participação das representações das comunidades da área da Resex, de movimentos sociais de São Luís e de lideranças camponesas, de pescadores e pescadoras, indígenas e quilombolas, do Conselho Indigenista Missionário (CIMI), de representantes de sindicato de trabalhadores e trabalhadoras rurais, que reunidos após o Encontro da Teia de Povos e Comunidades Tradicionais do Maranhão, participaram também desta assembleia. 0 relato de suas experiências de luta política em outras regiões do Maranhão, inspiraram a deliberação pela criação da Resex de Tauá-Mirim sob o princípio da autonomia política dos povos tradicionais. Foi criado também, na mesma ocasião, o Conselho Gestor da RESEX composto por representantes das comunidades e de movimentos sociais diversos. Desde 2017, o Conselho Gestor tem organizado reuniões mensais nas diferentes comunidades que compõem a Reserva Extrativista, discutindo a importância des- ta modalidade de Unidade de Conservação para as futuras gerações e, também, durante este período foi apresentada e elaborada a proposta do Estatuto da RESEX, baseando-se nas experiências de outras Reservas Extrativistas.

0 ato de criação do Conselho, além de se constituir como uma estratégia mais ampliada de luta em busca da garantia de proteção jurídica dos territórios ameaçados, foi também uma forma de manter a mobilização contínua para instalação da Reserva Extrativista, demandada oficialmente desde 2003. Este ato, conforme o depoimento de seus membros, se constituiu num marco político importante, pois o Conselho Gestor se tornou um espaço público significativo de discussões, de aprendizado e de decisões coletivas referentes aos interesses das comunidades, e simbolicamente relevante devido ao seu formato organizativo, tendo por base os princípios da autonomia política na perspectiva de enfrentamento às forças hegemônicas que ameaçam a perda dos territórios e dos modos de vida, orientando a unidade de lideranças e moradores de um modo geral pelo "sentimento de pertencimento" em contrapartida dos investimentos empresariais. E, diante das demandas e de contínuas ameaças ao território das comunidades inseridas na área da Reserva Extrativista de Tauá-Mirim, o Conselho Gestor, entre 2017 e 2018 criou a Associação da Casa das Águas, seguida da eleição da diretoria que foi sendo formada a partir das representações das diferentes comunidades.

Para além dos canais institucionais de garantias formais de direitos, as variadas experiências de ação coletiva para reivindicar o território têm mostrado que a mobilização política, na avaliação das lideranças, é o que tem garantido a permanência das comunidades em seus territórios. Tanto 
na experiência do Reage São Luís (2004 a 2006), quanto na experiência do Movimento de Defesa da Ilha, criado em $2015^{11}$, suas ações têm sido avaliadas por seus próprios ativistas como fundamentais no sentido de manter o debate público sobre a cidade na agenda política dos governos locais, observando-se que as contestações quebram as expectativas dos agentes econômicos (locais e internacionais), de que suas ambições estariam garantidas sem questionamentos. Estas experiências colocam em relevo algumas questões mais gerais para uma agenda de pesquisa, mas também de ordem político-pragmática aos movimentos. Dentre elas, indaga-se como conciliar as ações de mobilização contestatória e de denúncias por meio de canais institucionais, a exemplo de Conselhos, como é o caso do Conselho da Cidade de São Luís (CONCID) e outros espaços como as audiências públicas que têm caráter consultivo. Recorrendo à Tatagiba (2009), esse tipo de indagação e desafios em compreender as "interações sistêmicas” dos movimentos de contestação e suas articulações e diálogos com as ins- titucionalidades nos remete à necessidade de um entendimento mais amplo sobre a dinâmica e o contexto histórico e político dos movimentos, tendo por base as experiências variadas de movimentos sociais no Brasil, que exigiram a redemocratização do país ao longo dos anos de 1970 e, posteriormente, com a Constituição de 1988 e a criação de inúmeros canais formais de participação (TATAGIBA, 2009).

\section{Dom e persistência: uma luta do tama- nho da vida}

E outro dá as vezes pra ser um lutador... em defesa da vida, da vida! Eu acho que eu nasci pra isto. A gente... é um dom mesmo, que Deus deu pra gente [...]. E, além disso, uma necessidade muito grande que a gente teve de se engajar nessa luta (Libânio Pires, liderança de Santa Rosa dos Pretos, entrevista em 2015).

Podemos pensar, a partir das reflexões de Seu Libânio ${ }^{12}$, que se constituir como um lutador uma vida inteira é dom e dever de

11. Trata-se de um movimento criado em 2015 a partir das coalizões produzidas pela resistência do Cajueiro e pela retomada da pauta da Resex de Tauá-Mirim em maio do mesmo ano. Atualmente, o MDI tem questionado a proposta do Plano Diretor de São Luís apresentada pela Prefeitura que pretende converter cerca de 41\% da área hoje definida pela Lei de Zoneamento como Zona Rural em Zona Urbana. Os membros do MDI se reúnem mensalmente para discutir os problemas de interesse público, envolvendo os quatro municípios da Ilha, mas em função das discussões sobre o Plano Diretor de São Luís, atualmente têm se voltado mais para as intervenções sobre essa temática nas reuniões do Conselho da Cidade (CONCID), no qual o Movimento tem assento, bem como nas Audiências Públicas.

12. As reflexões sobre o que é ser um lutador e um homem negro derivam de várias conversas com seu Libânio nos últimos quatro anos. Seu Libânio é ancião da comunidade quilombola Santa Rosa dos Pretos e importante liderança comunitária da região de Itapecuru-Mirim. Esteve envolvido em inúmeras lutas no Sindicato dos Trabalhadores Rurais, em movimentos ligados à Igreja Católica e à organização a comunidades negras rurais. 
um homem negro que nasceu no seio das lutas travadas frente à violência das expropriações vivenciadas pela sua comunidade, cinquenta anos após o início de processos de afırmação territorial de grupos negros nas margens do Rio Itapecuru, em Itapecuru Mirim - MA. Mais do que isso, é retomar na ação corporal de tocar o tambor num bloqueio da ferrovia, de fechar a estrada de ferro mais de uma semana, de ocupar o prédio do INCRA, de viajar para as formações da Ação Cristã do Meio Rural, de fundar o Sindicato dos Trabalhadores Rurais, de não baixar a voz, de fazer da fala um instrumento de insurgência ${ }^{13}$ - os projetos de liberdade inventados no pós-cativeiro ${ }^{14}$. Pois:

eles ainda falam na democracia, eu digo pra mim: não existe ainda democracia, que a democracia ela traz vários sentidos .... Quando você está bem e eu estou mal, não existe democracia; quando hoje nós vemos ainda que a força maior sofre na mão da força menor, ainda não tem democracia (Libânio Pires, liderança de Santa Rosa dos Pretos, entrevista em 2015).

As problematizações levantadas por Cunha e Gomes (2007) sobre a "liberdade" e a "cidadania" no contexto de mudança jurídica do fim de um regime de servidão, nos incitam a pensar a colonialidade do poder como expressão permanente, marca du- radoura, contra a qual a luta de seu Libânio ganha sentido. Na análise de Seu Libânio, a tal liberdade formal, expressa no texto legal de 1888, se opõe à democracia - num compasso estranho em que onde toca uma, não toca a outra.

A ausência de vínculos de submissão, a distensão de hierarquias legais de subordinação no plano jurídico consensual, bem como o desaparecimento dos textos e instrumentos burocráticos que legitimaram a suspeição são essas de fato as marcas da restauração de um direito primordial? Certamente que não. A liberdade não foi restaurada; ao contrário, foi inventada e experimentada por aqueles que não há conheciam. Por isso, o território da liberdade é pantanoso e muitos dos sinais que sacralizaram a subordinação e a sujeição tornaram-se parte de um ambíguo terreno no qual ex-escravos e "livres de cor" tornaram-se cidadãos em estado contingente: quase cidadãos (CUNHA; GOMES, 2007, p. 13).

Os negros de Santa Rosa vivenciaram um tempo "pós-cativeiro" que é narrado como de "liberdade". A luta de seu Libânio fala das transformações que distanciaram esse tempo da realidade do quilombo. No período que se seguiu a abolição formal da escravatura no Brasil, os negros que trabalharam para o Barão de Santa Rosa na condição de escravos em suas lavouras de

13. Ver: BRUSTOLIN, C. DURAN, S.; SILVA, S. Silenciamento e insurgência: podem os quilombolas falar? I Seminário Internacional Povos e Comunidades Tradicionais Frente a Projetos de Desenvolvimento e o V Seminário: Desenvolvimento, Modernidade e Meio Ambiente. GEDMMA/UFMA, 20 a 23 de março de 2018. 14. Utilizamos o termo "pós-cativeiro" para contrapor ao período de relativa autonomia que marca a trajetória do grupo que pode se confundir ou não com a abolição formal da escravatura. 
cana, algodão, arroz, entre outras, constituíram suas vidas no espaço territorial relativamente autônomo de "uma légua de fundos e meia légua de frente” sobre as terras que teriam abrigado a fazenda (a casa, o cativeiro e as lavouras). Ou seja, nas últimas terras de lavoura da fazenda Santa Rosa que foram deixadas em testamento, em 1898, por Joaquim Nunes Belfort, aos negros. Na transcrição do testamento (datada de 1925), encontramos o seguinte:

" $1^{\circ}$ Reconheço aqui solenemente por meu filho a Américo Nunes Belfort havido durante minha viúves de América Henriques, mulher livre e solteira.

$2^{\circ}$ Deixo para uso e fructo de América Henriques e todos os seus filhos a data de terras dita no logar Santa Rosa, lado esquerdo do rio Itapicuru, na segunda légua ao fundo, onde tive o último estabelecimento de lavoura, com uma légua de fundos e meia légua de frente, podendo roçar nas mesmas terras, sem ônus algum, todos aquelles que me serviram como escravos, durante sua vida e a dos seus, não podendo em tempo algum serem vendidas, alienadas, ou dadas a pagamento as ditas terras que constituem um patrimônio perpétuo aos acima declarados e seus descendentes (transcrição citada por: LUCCHESI, 2008).

A princípio, a conquista da liberdade, com o final do regime escravista no Brasil em 1888, e a segurança territorial, operada com o testamento deixado pelo Barão, foram vivenciadas e significadas na consti- tuição de um território negro. Nessas terras, "ninguém pagava renda" ${ }^{15}$, nem mesmo os "de fora" que chegavam pedindo morada. Conforme Lucchesi (2008), “a permissão para roçar no território era concedida pelos membros mais velhos do grupo negro, que estipulavam também as normas de convivência e trabalho". No caso de alguém de fora se colocar nas terras, dependia de consentimento e "não poderia plantar planta de espinho", conforme Seu Benedito (Entrevista realizada, 2015).

0 testamento foi guardado por anos pelos mais velhos. Na década de 1950, após uma disputa com um posseiro que rompia frequentemente as normas ao roçar na cabeceira de um Igarapé, uma procuração foi repassada para o então prefeito do município de Itapecuru Mirim, que acabou realizando o desmembramento das terras herdadas e a venda para estranhos.

Buscando resolver a situação com o posseiro, Seu Urbano passou uma procuração a João da Silva Rodrigues em julho de 1952. Além de dar poder de representação para propor ação de despejo contra Teodoro Moreno, a procuração dava poderes ao "dito procurador propor outra qualquer ação contra o citado Teodoro Moreno, bem como promover a demarcação do dito imóvel [Santa Rosa]" (Autos de Demarcação da Data Santa Rosa, 1952: 5 in: LUCCHESI, 2008).

A década de 1950 marca uma série de transformações no território e o início da perda das terras e da liberdade, recolocan-

15. Há referência ao pagamento de renda a um dos filhos do Barão com uma das escravizadas. No entanto, os demais herdeiros de Santa Rosa se insurgiram contra ele (Entrevista com Seu Benedito, 2018) 
do ao grupo condições gestadas no sistema escravista. Ao Itapecuru Negro e Cultural se opõe o Itapecuru Branco e Comercial. Nas palavras de Libânio: "esse (último) não é o Itapecuru verdadeiro”.

A sina firmada com a Lei de Terras de 1850 ao campesinato aparece retomada aos negros de Santa Rosa. A posse do grupo não é respeitada, a cláusula de inalienabilidade do testamento e a referência à doação aos negros desaparecem do documento nos autos do processo de desmembramento. Com batalhas que escapam à lógica da resistência até então empreendida pelo "tronco velho", as regras gestadas para a manutenção do território (como a decisão dos mais velhos sobre os pedidos de morada, a proteção das cabeceiras dos Igarapés, o conhecimento dos marcos que delimitam a herança) não conseguem se sobrepor à nova ordem imposta à localidade e sucessivas perdas territoriais acontecem. Seu Libânio nasce aí, quando as lutas da senzala precisam ser retomadas, quando a liberdade se fragmenta na realidade da humilhação, do desrespeito, da mentira forjada nas letras, da hierarquização racial e social dos padrões de humanidade e de civilização que marcam a colonialidade.

Como destaca Lucchesi (2008), "praticamente todo o Vale do Itapecuru passou por um processo de demarcação judicial" que ficou conhecido como o tempo do demarque. A década de 1950 marca o início de uma mudança no regime territorial predominante no Maranhão. Dez anos antes, apenas 10\% das terras "estavam nas mãos de particulares e o restante era ocupado por posseiros dedicados à lavoura de subsistência” (LUCCHESI 2008; PEDROSA, 2007).

\subsection{A legalização da usurpação das terras dos pretos de Santa Rosa}

A década de 1950 pode ser tomada como marco do processo de perda de terras em Santa Rosa dos Pretos, perda que deve ser pensada a partir das relações assimétricas que envolvem as possibilidades de manutenção territorial do grupo e a usurpação das terras, relacionada ao forte interesse comercial e logístico que a região volta a despertar e as modificações no regime normativo territorial que deram sustento. A região, que foi um importante espaço produtor de gêneros agrícolas para a exportação no período colonial formal, encontrando-se em decadência no final do século XIX, passa a ser incluída novamente nas rotas comerciais, a partir de 1950, e nos projetos de desenvolvimento nacionais, com a abertura de uma estrada federal, com a instalação de fazendas e com a posterior constituição do Corredor Carajás.

0 esquadrinhamento do espaço territorial entre fazendas e estradas e a expropriação das terras por particulares e pelo Estado passam a ocorrer de forma veloz. Nos trinta anos que seguiram às primeiras perdas territoriais, já era possível encontrar sobre as léguas de Santa Rosa a ferrovia Transnordestina, a estrada rodoviária BR-135, fazendas, cinco linhões de energia e a estrada ferroviária da então CVRD (Companhia Vale do Rio Doce), empresa pública, hoje Vale S.A. privatizada desde 1997, um assentamento da reforma agrária. 0 território passou a ser gradualmente marcado pela construção de um "corredor" que permite o escoamento de commodities, como o minério de ferro e grãos, do interior do país para o litoral, especificamente, para o porto do Itaqui e para o Terminal Portuário da Ponta da Madeira, em São Luís.

A construção da rodovia e da estrada de ferro impactaram profundamente o territó- 
rio. Juntamente com a entrada de fazendeiros nas terras, especialmente, a apropriação feita por João Rodolfo (maior proprietário de terras no local), as perdas territoriais corresponderam a cerca de 80\% da área, no cálculo de Seu Libânio. As perdas territoriais relacionadas à logística dos empreendimentos e à instalação de fazendeiros diminuíram as áreas de posse do grupo e, mais do que isso, destruíram espaços de roça, secaram igarapés, eliminaram árvores frutíferas. Novas dinâmicas de reprodução da vida no local foram impostas, deslocando um campesinato negro assentado às margens do rio Itapecuru do espaço de relativa autonomia para uma área de confronto, e nisso, restaurando as dinâmicas coloniais de sujeição.

No quadro dessas dinâmicas, o testamento não produziu efeitos de direito. A inalienabilidade com cláusula, no sistema oficial de justiça, e como memória, no lo$\mathrm{cal}^{16}$ - insistentemente repetida nas tentativas que se seguiram de permanecer no território - foi constantemente anulada pelos papéis, pelas cercas colocadas pelos fazendeiros, pelas estradas que secaram Igarapés. Como em muitos outros casos envolvendo comunidades negras, a posse dos papéis que deveriam legitimar e garantir contra terceiros a propriedade das terras nunca se constituiu em garantia de direitos territoriais. A colonialidade opera a partir de mecanismos que possibilitam a anulação: os sistemas de justiça não abarcam nem garantem os di- reitos dos negros da Santa Rosa.

Contra a nova ordem imposta, a luta foi o caminho e se constituiu em repertório de ação. Além dos enfrentamentos cotidianos e da procura pelos documentos em cartórios, pode-se pensar em dois momentos da luta pela afırmação territorial. 0 primeiro que compreende uma série de formações ligadas aos movimentos de base no meio rural da Igreja Católica e a organização do sindicato dos trabalhadores rurais. Na resistência fomentada nos encontros, a ACR alertava principalmente para a permanência na terra, para a necessidade de assegurar as posses das terras que estavam com os camponeses. Em um espaço muito reduzido e sofrendo forte pressão, os negros de Santa Rosa resistiram. Na volta de cada encontro da ACR, as lideranças passavam para os que tinham ficado na comunidade a importância de permanecer naquele chão.

A posse da terra e a organização dos camponeses foi central na manutenção de um importante núcleo territorial que continuou se reproduzindo e principalmente reorganizando a memória sobre o local. 0 Igarapé de Madalena que abastecia a comunidade com água e peixes ficou dentro da fazenda de Sr. Rodolfo e foi canalizado para construção de um açude. Os moradores, mesmo impedidos de entrar na fazenda, o chamam de açude de Madalena, fazendo com que a memória não deixe de se insurgir contra as cercas.

16. Em muitas situações, a referência local ao testamento e a cláusula de inalienabilidade é acionada como memória subterrânea, no sentido dado por Pollak (1989), no confronto com os processos de titulação particulares que incidiram sobre o território. 
O testamento não alcançou a validade jurídica necessária para proteger a área territorial. Para além de ter um documento, está em jogo fazer valer o papel em um sistema em que são constantemente destituídos do domínio dos códigos formais e informais. Os empreendimentos chegaram e avançaram sobre o território sem a necessidade de "fazer mitigações”, "avaliar impactos" ou ouvir a comunidade. As primeiras estradas e os linhões de energia chegaram prometendo o "progresso" e o "desenvolvimento" da localidade. Uma "canoa furada" em que embarcaram, como analisa hoje seu Libânio. É interessante pensar que a expansão do capital sobre regiões, como as ocupadas pelas comunidades negras de Itapecuru, está relacionada à luta que se desdobrará nas décadas seguintes pela afirmação de direitos às comunidades tradicionais no Brasil e ao reconhecimento de direitos aos quilombolas em 1988. As legislações que protegem direitos aos territórios tradicionais são estabelecidas com a Constituição Federal de 1988. Portanto, as possibi- lidades de grupos negros como o de Santa Rosa se colocarem como sujeitos de direitos territoriais estavam relacionadas, nesse primeiro momento, a uma legislação forjada, em 1850, para o não reconhecimento, e à luta camponesa pela terra e pela afırmação jurídica de direitos territoriais e pela reforma agrária.

Um segundo momento da luta corresponde ao final da década de 1980 , com as formações e trabalhos das lideranças de Santa Rosa junto ao Centro de Cultura Negra do Maranhão (CCN) ${ }^{17}$ e ao Projeto Vida de Negro $(\mathrm{PVN})^{18}$. As lideranças de Santa Rosa dos Pretos ingressaram na luta pela consolidação de uma política às comunidades remanescentes de quilombos e pela titulação de seu território a partir do dispositivo constitucional (Art. 68 do ADCT da Constituição Federal de 1988). Participaram da formação da ACONERUQ (Associação das Comunidades Negras Rurais Quilombolas do Maranhão) e passaram a estabelecer uma série de relações com grupos negros de outras regiões.

17. 0 Centro de Cultura Negra do Maranhão foi criado em 1979, na sede da recém-criada Sociedade Maranhense de Diretos Humanos, a partir da reunião de "algumas pessoas negras preocupadas com a sistemática prática das mais diversas formas de discriminação racial” que "começaram a se reunir e discutir a questão, tendo por base as influências das informações que chegavam sobre a luta de libertação dos países africanos até então colonizados pelos europeus, e sobre a luta dos negros norte-americanos por direitos civis, além das notícias trazidas pelos que viajavam ao sul/sudeste do Brasil sobre o surgimento de organizações do Movimento Negro" (http://ccnma.org.br/index.php/about/historico-ccn).

18. 0 Projeto Vida de Negro foi realizado pela Sociedade Maranhense de Direitos Humanos e pelo Centro de Cultura Negra do Maranhão. As atividades de campo ocorreram inicialmente no período de abril de 1988 a julho de 1989 no estado no Maranhão. Teve como objetivos iniciais: - mapeamento das terras de preto e resgate histórico das mobilizações dos negros (resistência, formas de organização, estratégias de sobrevivência e manifestações culturais)". Diante dos cenários encontrados o projeto sofreu modificações: "considerando a tragicidade dos acirrados conflitos, observados no campo em relação à questão fundiária, e com base na nova Constituição Brasileira, adaptamos o PVN, enlarguecendo as perspectivas de seu retorno prático às comunidades em estudo, sem entretanto mutilar seus princípios fundamentais - pelo contrário: enriquecendo-os" (Projeto Vida de Negro, 2002). 
Uma série de procedimentos administrativos foram formalizados a partir do final da década de 1980. A institucionalização do pleito de regularização fundiária do território quilombola de Santa Rosa dos Pretos no INCRA, em 2005, amparada na luta das comunidades negras rurais no Maranhão e apoiada por instituições do movimento negro e dos direitos humanos, deslocou, em parte, o campo de tensões das esferas locais de enfrentamento, como a manutenção da posse, para a pressão sobre o órgão público para um pleito institucional, o cumprimento das etapas do processo administrativo. A luta e as esperanças passaram a ter como foco o avanço do processo de regularização fundiária instaurado no INCRA para a retomada do território. No entanto, o processo de regularização fundiária do território de Santa Rosa dos Pretos, como de outras comunidades negras brasileiras, que reivindicam direitos territoriais, começou, anos após as primeiras peças técnicas, a ficar estagnado.

$\mathrm{Na}$ última década, foram propostos e iniciados projetos de instalação de duas novas obras que complementam o Corredor Carajás e adentram o território de Santa Rosa: a duplicação da BR-135 e a duplicação da Estrada de Ferro Carajás. A princípio, a chegada de novos empreendimentos poderia configurar um cenário um pouco distinto daquele da implantação na década de 1950 da rodovia e na década de 1980 da Estrada de Ferro Carajás. 0 território Santa Rosa já seria reconhecido por instâncias como a Fundação Cultural Palmares e o INCRA e poderia contar com uma série de proteções jurídicas que não possuía antes. A trajetória de algumas lideranças incluiria uma série de formações políticas e engajamentos em sindicatos e entidades não governamentais. No entanto, em um proce- dimento de continuum colonial, tal como na situação que envolveu o testamento, o processo de reconhecimento do território quilombola (apesar do direito formalizado) foi constantemente anulado: nos primeiros estudos ambientais para a duplicação da estrada de ferro, a existência dos quilombolas foi desconsiderada. Foram apenas a luta, como as ocupações e protestos realizados, e a persistente ida de lideranças e denúncia junto aos órgãos como o MPF (Ministério Público Federal) e a DPU (Defensoria Pública da União), bem como as relações com a entidade Rede Justiça nos Trilhos (JnT) que abriram uma discussão sobre impactos e violações. A legislação quilombola vem sendo desconstituída como possibilidade de tensionamento também no processo de duplicação da BR-135. As obras iniciaram sem consulta prévia, sem audiências e um grande núcleo do território (cerca de 345 estabelecimentos) foi classificado como estando em área de domínio do DNIT (Departamento Nacional de Infraestrutura e Transporte), órgão da União, portanto, na interpretação dos técnicos, sujeito à remoção sem receber pela terra.

A luta de Libânio, portanto, não sossegou. No INCRA, em reuniões da associação, nos trilhos do trem (se o respeito aos direitos exigir), em conversas na frente de sua casa ou na igreja, apesar de quase cego, seu dom para enxergar as injustiças e não desanimar estão firmes, e a precisão do seu povo continua. 0 que mais dói é como dispositivos raciais próprios da colonialidade operam não somente a partir de "fora" da comunidade, mas começam a penetrar na esfera das relações locais entre os familiares, prometendo emprego e um futuro que Libânio afırma só existir com liberdade. 


\section{Considerações finais}

No Maranhão, assiste-se nos últimos sessenta anos à progressiva construção de estradas rodoviárias e ferroviárias, que cruzam o estado com o objetivo de permitir a circulação de mercadorias para exportação, e de portos, que complementam a estrutura de escoamento para o mercado exterior. A instalação desses empreendimentos sobre os territórios tradicionais de quilombolas, de pescadores, de camponeses e de indígenas permite visualizar processos de expansão capitalista amparados sobre estruturas coloniais que hierarquizam a necessidade das obras, a partir de discursos que sustentam suas potencialidades desenvolvimentistas, e apagam e minimizam as histórias locais e os processos produtivos e culturais ali gestados.

Por um lado, a construção de estruturas logísticas amparadas em discursos desenvolvimentistas ganha eco nas instâncias estatais e amplo apoio governamental. Os processos de licenciamento avançam, sem cumprir as etapas previstas na legislação nacional, fruto de lutas de diferentes grupos sociais no Brasil e no exterior, como os protocolos de Consulta Prévia. As máquinas chegam para destruir casas de moradores no Cajueiro, como chegam para iniciar a duplicação da BR-135 em Itapecuru-Mirim.

A pergunta - "Como vocês ficaram sabendo da obra”? - permite problematizar os processos que envolvem a instalação desses empreendimentos e o respeito aos direitos territóriais dos grupos atingidos, uma vez que a resposta quase sempre indica que as máquinas chegaram antes que os papéis ou as reuniões, indicando processos de violência direta, de expulsão, que não se amparam nem mesmo em ritos institucionais em nome da universalidade das obras - do "ne- cessário" desenvolvimento. Tentando provocar um silêncio absurdo das vozes que estão sobre esses territórios e apagar suas histórias, reencenando processos civilizatórios sobre vidas sem importância e terras a serem exploradas, os ritos institucionais muitas vezes vêm a reboque dos processos de instalação para oficializá-los. Como destacado neste artigo, as comunidades da Zona Rural de São Luís impediram uma audiência pública que consideravam ter sido organizada e agendada de forma ilegal. Mesmo assim, a SEMA-MA convocou, em seguida, a audiência para a sede de um batalhão de polícia.

As reações dos povos/comunidades da RESEX Tauá-Mirim e do Quilombo Santa Rosa dos Pretos contra as formas de expropriação dos seus territórios e da desqualificação dos seus modos e meios de vida atualizam lutas ancestrais contra a morte da vida material e cultural dos grupos que ali residem. Repertórios diversos de ação como ocupar uma BR - tensionam as estruturas coloniais de exclusão e o silenciamento desses grupos para a construção de esferas públicas de discussão, construindo algumas possibilidades de que, nas arestas dos espaços de poder que orquestram os processos de exclusão, suas histórias, seus espaços territoriais e suas vidas produzam sentidos e ganhem proteção.

\section{Referências}

ACSElRAD, H. HERCULANO, S. PÁDUA, J. A. Introdução: A justiça ambiental e a dinâmica das lutas socioambientais no Brasil - uma introdução. In: ACSELRAD, H. HERCULANO, S. PÁDUA, J. A. (Org.). Justiça ambiental e cidadania. Rio de Janeiro: Relume Dumará: Fundação Ford, 2004.

ALMEIDA, A. W. B. de. Refugiados do desenvolvimento: os deslocamentos compulsórios de in- 
dios e camponeses e a ideologia da modernização. Travessia. maio/agosto, 1996. pp. 30-35.

ALVES, E. de J. P. A. MARTINS, C. C. S. O Terreiro do Egito no contexto das lutas políticas contemporâneas na Ilha do Maranhão. Boletim da Comissão Maranhense de Folclore - CMF No 61 Dezembro, 2016; Acesso no link: http:// www.cmfolclore.ufma.br/site/wp-content/ uploads/2017/03/BOLETIM-DA-CMF-N\%C2\%BA61-DEZEMBR0-2016-ISSN-1516-1.

ALVES, E. de J. P. Repertórios e argumentos da mobilização política: um estudo sobre o Movimento Reage São Luís em São Luís-MA. XX f. 2014. Tese (Doutorado em Sociologia e Antropologia [Sociologia]) - Instituto de Filosofia e Ciências Sociais, Universidade Federal do Rio de Janeiro, Rio de Janeiro. 2014.

ALVES, E. de J. P. 2016. Modos de vida, territórios e uma cidade em questão: resistências políticas de comunidades rurais no municipio de São Luís - Maranhão, Brasil. L’Ordinaire des Amériques [En ligne], 221, mis en ligne le 18 novembre. Disponivel em http://orda.revues.org/3178; DOI : 10.4000/orda.3178. Consultado em 30.04.2018.

BAUMAN, Z. Vidas desperdiçadas. Trad. Carlos Alberto Medeiros. Rio de Janeiro: Zahar, 2005.

BOURDIEU, P. Les usages sociaux de la science. Pour une sociologie clinique du champ scientifique. Paris: Institut Nacional de La recherche Agronomique (1997).

BRUSTOLIN, C. DURAN, S. e SILVA, S. Silenciamento e insurgência: podem os quilombolas falar? I Seminário Internacional Povos e Comunidades Tradicionais Frente a Projetos de Desenvolvimento e o V Seminário: Desenvolvimento, Modernidade e Meio Ambiente. GEDMMA/ UFMA, 20 a 23 de março de 2018.

EGLISH, B. A. Alcoa na Ilha: um documento acerca das implicações sociais, econômicas e ambientais da implantação de uma indústria de alumínio em São Luis do Maranhão. São Luis: Cáritas Brasileira, 1984.

ESCOBAR, A. La invención del tercer mundo: construcción e desconstrucción del desarrollo. Caracás, Fundación Editorial El Perro y la rana, 2007.

FERRETTI, M. O Terreiro do Egito e o navio encantado de Dom João. São Luís. Boletim da Comissão Maranhense de Folclore, n59, dez/2015.

FOUCAULT, M. Em defesa da sociedade: curso no Collège de France (1975-1976). Trad. Maria Ermantina Galvão. São Paulo: Martins Fontes, 1999.

GEDMMA, Relatório Socioantropológico. RESEX de Tauá-Mirim: Cajueiro e outras comunidades tradicionais na luta por justiça e direitos territoriais, Zona Rural II, Universidade Federal do Maranhão, São Luís/MA - Brasil, 2014. São Luís, 2014. $45 \mathrm{p}$

GISTELINCK, F. Carajás: usinas e favelas. São Luís: Minerva. 1988

GOMES, F. dos S. e OLIVIA, O. M. Introdução. Quase Cidadão - Histórias e Antropologias da Pós- Emancipação no Brasil. Rio de Janeiro, FGV, 2007.

GUDYNAS, E. Extractivismos en América del Sur y sus efectos derrame. Boletín $n^{\circ} 76,2015$ societe suisse des americanistes / schweizerische amerikanisten - gesellschaft. Disponivel em: http:// gudynas.com/wp-content/uploads/GudynasExtractivismosEfectosDerrameSSA2016.pdf

HERCULANO, S. PACHECO, T. (Orgs.). Racismo Ambiental: I Seminário Brasileiro sobre Racismo Ambiental. Rio de Janeiro: FASE, 2006.

IBAMA. Laudo Sócio-Econômico e Biológico para Criação da Reserva Extrativista do Taim. Instituto Brasileiro do Meio Ambiente e dos Recursos Naturais Renováveis - IBAMA-MA. São Luís, 2007.

JESUS, T. S. C. de. Violência, Memória e Resistência: análise do conflito pela terra em Rio dos Cachorros, São Luís - MA (1996 - 2013). Monografia curso de História. São Luís: UFMA, 2014. Mimeo.

LEROY, J. Prefácio. In: HERCULANO, Selene; 
PACHECO, Tânia (Orgs.). Racismo Ambiental: I Seminário Brasileiro sobre Racismo Ambiental. Rio de Janeiro: FASE, 2006.

LUCCHESI, F. Relatório Antropológico de Identificação do Território Quilombola de Santa Rosa (MA). Brasília. INCRA, 2008.

MAGALHÃES, S. Lamento e Dor. Uma análise sócio-antropológica do deslocamento compulsório provocado pela construção de barragens. Tese de Doutorado. Programa de Pós-Graduação em Ciências Sociais - PPGCS/UFPA. Belém: UFPA, 2007.

MARANHÃO. Governo do Estado do Maranhão. Agenda Operacional do Polosider, 2004.

MENDONÇA, B. R. Continuum Colonial: colonialidade (= modernidade), empreendimentos capitalistas, deslocamentos compulsórios e escravos da república no estado do Maranhão, Brasil. São Luís: PPGCSOC/UFMA, 2017. Tese de doutorado. Mimeo. 313p.

MIRANDA, A. C. P. Unidades de conservação da natureza $\mathrm{x}$ Indústrias potencialmente poluidoras: o caso da implantação da Reserva Extrativista de Tauá-Mirim. In: SANT'ANA JÚNIOR; H. A.; PEREIRA, M. J. F.; ALVES, E. J. P.; PEREIRA, C. R.

A. (Orgs.). Ecos dos conflitos socioambientais: A RESEX de Tauá-Mirim. São Luís - MA: EDUFMA, 2009.

PICOLI, F. O Capital e a devastação da Amazônia. São Paulo: Expressão Popular, 2006.

POLLAK, M. Memória e identidade social. Estudos históricos, Rio de Janeiro, v. 5, n. 10, 1992, p.

200-212.

PORTO GONÇALVES, C. W. O Campo se Manifesta A Questão (da Reforma) Agrária. In: Relatório Conflitos por Terra, CPT, 2014.

ROBINSON.W. Una Teoría sobre el capitalismo global. Producción, classe y Estado en un mundo transnacional. Traduccion de Victor Acuña Soto y Myrna Alonzo Calles- México. Siglo XXI Editores, 2013.

SANT'ANA JÚNIOR; ALVES, E. de J. P. Mina-ferrovia-Porto: no "fim de linha", uma cidade em questão. In ZHOURI A. (Org.) Mineração: violências e resistências [livro eletrônico]: um campo aberto à produção de conhecimento no Brasil. Marabá, PA; iGuana; ABA, 2018.

SBRANA. Darlan Rodrigo. A Ilha antes de São Luís: localização das aldeias tupinambás da Ilha Grande do Maranhão (século XVII). São Luís: FAPEMA/UFMA, 2015. Prêmio FAPEMA, 2015.

TARROW, S. El poder en movimiento. Los movimientos sociales, la acción colectiva y la política. Madri: Alianza Editorial, 1997.

TATAGIBA, L. Relação entre movimentos sociais e instituições políticas no cenário brasileiro recente. Reflexões em torno de uma agenda preliminar de pesquisa. In: ALVAREZ, S. BAIOCCHI, G. LAÓ-MONTES, A. RUBIN, J. W. and THAYER, M. Interrogating the Civil. Society Agenda: Social Movements, Civil Society, and Democratic Innovation. 2009.

ZHOURI, A. Introdução. Produção de conhecimento em um 'campo minado'. In ZHOURI, A (Org.) Mineração: violências e resistências [livro eletrônico]: um campo aberto à produção de conhecimento no Brasil. Marabá, PA. iGuana; ABA, 2018.

ZHOURI, A; OLIVEIRA, R. Quando o lugar resiste ao espaço. Colonialidade, modernidade e processos de territorialização. In ZHOURI, A. e LACHEFSKI, K. (org.). Desenvolvimento e Conflitos Ambientais Belo Horizonte: Editora UFMG, 2010. Sites Visitados:

http://www.brasil.gov.br/infraestrutura/2016/01/ governo-autoriza-novo-terminal-de-uso-privadono-maranhao. Acesso em 12.01.2016

http://gudynas.com/wp-content/uploads/GudynasExtractivismosEfectosDerrameSSA2016.pdf. Acesso em 30.04.2018 


\section{RESUMO}

Neste artigo, exploramos dimensões da colonialidade de poder expressas nos processos de dominação engendrados na instalação de estruturas logísticas para o escoamento de mercadorias para exportação - como o minério de ferro e produtos do agronegócio - que atravessam o estado do Maranhão rumo aos mercados internacionais. Desde a década de 1950, começaram a ser implantadas rodovias federais, estradas de ferro e portos na região, relacionadas às políticas desenvolvimentistas dos governos brasileiros. Essas obras foram executadas sobre espaços territoriais que abrigam uma diversidade de povos e comunidades tradicionais, provocando deslocamentos, eliminando espaços de roças, entupindo igarapés. Nos últimos anos, as estruturas criadas entre as décadas de 1950 e 1980, principalmente, começaram a ser ampliadas, duplicadas e também novos projetos passaram a ser executados, com forte interesse do capital internacional. As propostas amparam-se sobre a imagem desses espaços territoriais como espaços vocacionados para exercerem a função de portos e estradas. Exploramos, também, repertórios de ação elaborados contra essas investidas de expansão do capital sobre territórios tradicionais, evidenciados numa série de processos de resistência. As dimensões da colonialidade e os repertórios de ação serão explorados a partir da discussão da ampliação de estruturas logísticas e de processos de resistência engendrados na Zona rural II, de São Luís, e no território negro de Santa Rosa dos Pretos, em Itapecuru Mirim.

\section{PALAVRAS-CHAVE}

Grandes empreendimentos - Expansão territorial - Comunidades tradicionais

\section{ABSTRACT}

In this article, we explore dimensions of the coloniality of power expressed in the processes of domination engendered in the installation of logistics structures for the flow of goods for export - such as iron ore and agribusiness products - that cross the state of Maranhão towards international markets. Since the 1950s, federal highways, railroads and ports in the region began to be implemented, related to the development policies of Brazilian governments. These works were executed on territorial spaces that shelter a diversity of traditional peoples and communities, provoking displacements, eliminating spaces of roças, clogging igarapés. In recent years, structures created between the 1950s and the 1980s, mainly, began to be expanded, duplicated, and also new projects were implemented, with keen interest from international capital. The proposals are based on the image of these territorial spaces as spaces designed to perform the function of ports and roads. We have also explored the repertoires of action against these investees of capital expansion over traditional territories, evidenced in a series of resistance processes. The dimensions of coloniality and action repertoires will be explored from a discussion of the expansion of logistic structures and resistance processes engendered in São Luís rural area II and the black territory of Santa Rosa dos Pretos, in Itapecuru Mirim.

\section{KEYWORDS}

Large enterprises - Territorial expansion Traditional communities

Recebido em: 08/05/2018

Aprovado em: 01/04/2019 